\section{Anorectal Traumas in Children}

\section{Gamedzi Komlatsè Akakpo-Numado ${ }^{1 *}$, Missoki Azanledji Boume $^{1}$, Bahoura Balaka ${ }^{3}$, Komlan Adabra ${ }^{2}$, Komlan Anani Mihluedo-Agbolan', Kokou Elom Marc Hervé Santos', Codjo Serge Metchihoungbe ${ }^{1}$ and Hubert Tekou ${ }^{1}$}

${ }^{1}$ Department of Pediatric Surgery, Sylvanus Olympio Teaching Hospital, BP 57 Lomé, Togo

${ }^{2}$ Department of General Surgery, Sylvanus Olympio Teaching Hospital, BP 57 Lomé, Togo

${ }^{3}$ Department of Pediatrics, Campus Teaching Hospital of Lomé, Togo

\section{Abstract}

\section{Introduction}

Anorectal Traumas (ART) are rare injuries in children. Reports from developing countries are also rare. Their etiologies are variable. Their management is based on a correct diagnosis including anorectal lesions and associated injuries in pelvis or abdomen. A colostomy can be indicated according to the grade of the injury. We herin report the experience of our department in Togo, a developing country.

\section{Methods}

This is a retrospective study on files of children aged 15 years or less, managed in Pediatric Surgery Department of Sylvanus Olympio Teaching Hospital of Lomé from January 2004 to December 2013 for ART. The classification of Black et al., was used. Age, sex, mechanism of the trauma, presentation, treatment and outcome were recorded.

\section{Results}

During 10 years, 4 children ( 2 girls and 2 boys) were treated in our Department for ART. Their ages were 2.5, 8, 11 and 13 years old. The etiology was impalement upon a picket in 2 cases and sexual assault in 2 cases. The delays to admission were 8 hours, 19 hours, 3 days and 6 days. Two traumas were of grade II, one of grade III and one of grade V. Colostomy was done in two cases (grades III and V). Two children didn't need anorectal repair (one of grade II and one of grade $\mathrm{V}$ ). Anorectal repair was done immediately in one grade II, and 4 week after colostomy in the grade III. Sigmoid and ileal perforation were repaired in the grade V. The outcome was good in all cases.

\section{Conclusion}

ART can be life threatening in children. Early and correct diagnosis and adapted management lead to recovery without sequela.

Keywords: Anorectal injuries; Anorectal traumas; Child; Impalement; Sexual assault

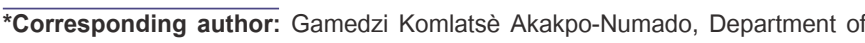
Pediatric Surgery, Sylvanus Olympio Teaching Hospital, S/C M Gameti K Evenyo 08 BP 80025 Lomé 8, Togo, Tel: 228 99493007, 228 91469833, 22823368107 Fax: 228 22213675; E-mail: akanugregoire@yahoo.fr, jerakan1671@gmail.com

Citation: Akakpo-Numado GK, Boume MA, Balaka B, Adabra K, Mihluedo-Agbolan KA et al., (2015) Anorectal Traumas in Children. J NCP 2: 004.

Received: October 08, 2014; Accepted: January 05, 2015; Published: January 19, 2015

\section{Introduction}

Anorectal Traumas (ART) are rare injuries in children [1-3]. Many publications are case reports $[2,4,5]$, or limited series of cases $[1,3,6]$. They are frequently due to accidental impalement $[1,2,4,5]$, sexual assault $[2,4]$ or road traffic accident [1,4 ]. Intra-pelvic [7] and intra-abdominal injuries [5] can be associated with ART, and threaten the life of the child. The right diagnosis of the ART and its associated injuries is not easy, but must be done in emergency, in order to avoid especially septic complications. Their management can require fecal diversion according to the delay to treatment, and the grade of Black et al., [8] of the injury. In developing countries, the difficulties of diagnosis and management are added to the long delay to consultation, and reports from those countries are rare [1]. Our study aimed at describing the presentation of ART in our department, our experience in their management and their outcome.

\section{Materials and Methods}

This is a retrospective study on files of children aged 15 years or less, treated in the Pediatric Surgery Department of the Sylvanus Olympio Teaching Hospital of Lomé (Togo) between January 2004 and December 2013. For each case, we indicated the age, the sex, the mechanism of the ART, the delay to treatment, the clinical presentation, the treatment and its outcome. The grade of the injury was described according to the classification of Black et al., [8]. We classified the outcome as "good" if healing without sequela especially fecal incontinence; "fair" if fecal incontinence, and "bad" if death occurred. Fecal incontinence was appreciated with the score of Jorge and Wexner [9] (Table 1).

\begin{tabular}{|l|c|c|c|c|c|}
\hline & Never & $<1 /$ month & $>1 /$ month & $>1 /$ week & $>1 /$ day \\
\hline $\begin{array}{l}\text { Incontinence to solid } \\
\text { stool }\end{array}$ & 0 & 1 & 2 & 3 & 4 \\
\hline $\begin{array}{l}\text { Incontinence to liquid } \\
\text { stool }\end{array}$ & 0 & 1 & 2 & 3 & 4 \\
\hline Incontinence to gases & 0 & 1 & 2 & 3 & 4 \\
\hline Wearing of diaper & 0 & 1 & 2 & 3 & 4 \\
\hline Lifestyle alteration & 0 & 1 & 2 & 3 & 4 \\
\hline
\end{tabular}

Table 1: Jorge and Wexner score for fecal incontinence [9].

NB: Score 0: absence of fecal incontinence; Score 20: Maximal fecal incontinence

\section{Results}

During 10 years, 4 children (2 boys and 2 girls) were treated for ART in the Department of Pediatric Surgery of Sylvanus Olympio Teaching Hospital of Lomé. The main features of the patients are presented in Tables 2 and 3.

The etiology of ART was sexual assault in two cases, and impalement on wood picket in two cases. Sexual assault was committed in the small boy by his step-father at home and in the girl by a stranger to her family near a market. As for impalements, the boy jumped from a wall onto the picket, and the girl fell from a tree onto the picket.

The diagnoses were essentially based on clinical presentation. Anuscopy was done in all patients under general anesthesia; it was 
added to vaginoscopy in girls. The rectovaginal septum was ruptured till the posterior vaginal fornix in patient 1 . It was a full-thickness injury without peritoneal involvement, and was classified grade III. The Patient 2 had no injury at the anal margin (Figure 1); he presented a superficial and linear detachment of the mucous membrane of the posterior wall of rectum, with blood coming far from the colon. Peritonitis signs were obvious. Plain abdominal radiograph didn't show free gas in the abdomen. The grade of this injury was précised at surgical exploration.

\begin{tabular}{|c|c|c|l|l|l|}
\hline Patient & Age (years) & Sex & $\begin{array}{l}\text { Etiology of } \\
\text { the ART }\end{array}$ & $\begin{array}{c}\text { Delay to } \\
\text { admission }\end{array}$ & Initial Symptoms \\
\hline 1 & 11 & $\mathrm{~F}$ & $\begin{array}{l}\text { Sexual } \\
\text { assault }\end{array}$ & 19 hours & $\begin{array}{l}\text { Vaginal and rectal } \\
\text { bleeding }\end{array}$ \\
\hline 2 & 13 & $\mathrm{M}$ & $\begin{array}{l}\text { Impalement } \\
\text { on a picket }\end{array}$ & 8 hours & $\begin{array}{l}\text { Rectal bleeding, } \\
\text { abdominal pain }\end{array}$ \\
\hline 3 & 8 & $\mathrm{~F}$ & $\begin{array}{l}\text { Impalement } \\
\text { on a picket }\end{array}$ & 6 days & $\begin{array}{l}\text { Vaginal and rectal } \\
\text { bleeding }\end{array}$ \\
\hline 4 & 2.5 & $\mathrm{M}$ & $\begin{array}{l}\text { Sexual } \\
\text { assault }\end{array}$ & 3 days & Rectal bleeding \\
\hline
\end{tabular}

Table 2: Recapitulation of features of patients treated for anorectal trauma in the order of their admission (Part 1).

ART: Anorectal Trauma; F: Female; M: Male

\begin{tabular}{|c|l|c|c|c|}
\hline Patient & Diagnosis at admission & $\begin{array}{c}\text { Grade } \\
\text { (Black) }\end{array}$ & Treatment & Outcome \\
\hline 1 & $\begin{array}{l}\text { Rupture of the RV } \\
\text { septum }\end{array}$ & III & $\begin{array}{l}\text { Colostomy, repair of } \\
\text { RV septum and CC }\end{array}$ & Good \\
\hline 2 & Peritonitis & $\begin{array}{l}\text { Laparotomy, repair } \\
\text { of sigmoid and ileal } \\
\text { perforation, colosto- } \\
\text { my, CC }\end{array}$ & Good \\
\hline 3 & $\begin{array}{l}\text { RV fistula after bad repair } \\
\text { of RV septum wound }\end{array}$ & II & $\begin{array}{l}\text { Repair of RV } \\
\text { septum }\end{array}$ & Good \\
\hline 4 & $\begin{array}{l}\text { Wound of anal margin } \\
\text { and posterior anal wall }\end{array}$ & II & $\begin{array}{l}\text { No operation Local } \\
\text { antiseptics }\end{array}$ & Good \\
\hline
\end{tabular}

Table 3: Recapitulation of features of patients treated for anorectal trauma in the order of their admission (Part 2).

CC: Closure of colostomy; RV: Rectovaginal

The etiology of ART was sexual assault in two cases, and impalement on wood picket in two cases. Sexual assault was committed in the small boy by his step-father at home and in the girl by a stranger to her family near a market. As for impalements, the boy jumped from a wall onto the picket, and the girl fell from a tree onto the picket.

The diagnoses were essentially based on clinical presentation. Anuscopy was done in all patients under general anesthesia; it was added to vaginoscopy in girls. The rectovaginal septum was ruptured till the posterior vaginal fornix in patient 1 . It was a full-thickness injury without peritoneal involvement, and was classified grade III. The Patient 2 had no injury at the anal margin (Figure 1); he presented a superficial and linear detachment of the mucous membrane of the posterior wall of rectum, with blood coming far from the colon. Peritonitis signs were obvious. Plain abdominal radiograph didn't show free gas in the abdomen. The grade of this injury was précised at surgical exploration.

The patient 3 was treated initially in a sick room by a nurse, who didn't make correct exam of the injury; he aimed to stop the bleeding, and did some stitches only at the anal margin (Figure 2). The bleeding stopped of course, but 3 days later, she developed a low rectovaginal fistula (Figure 3), with feces and blood coming out from anus and vagina. The grade of this injury was précised at surgical exploration.

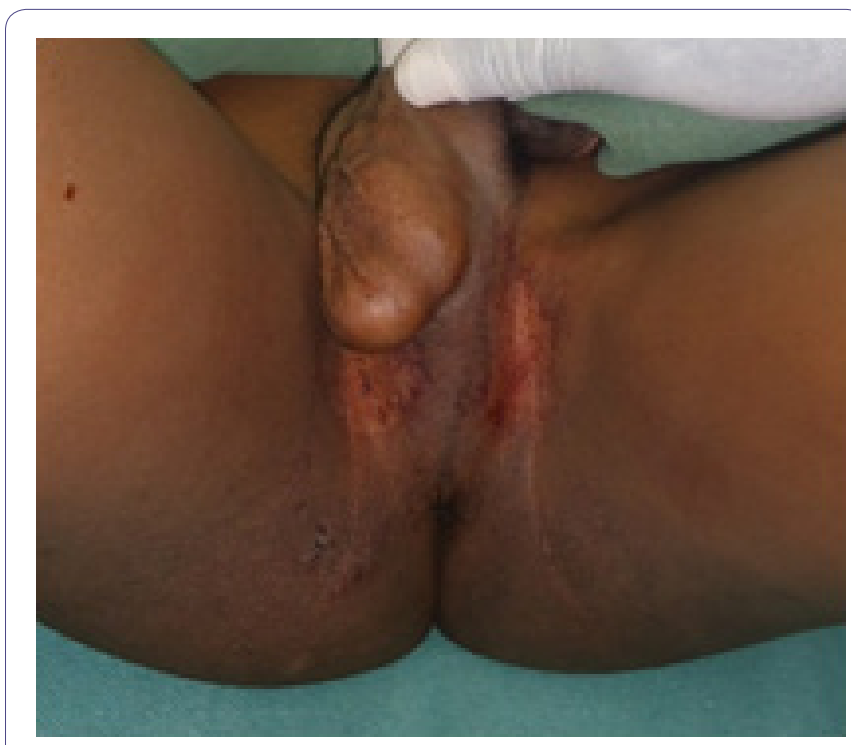

Figure 1: Anal margin without injury in the boy of 13 years old (Patient 2).

Note: Traces of blood.

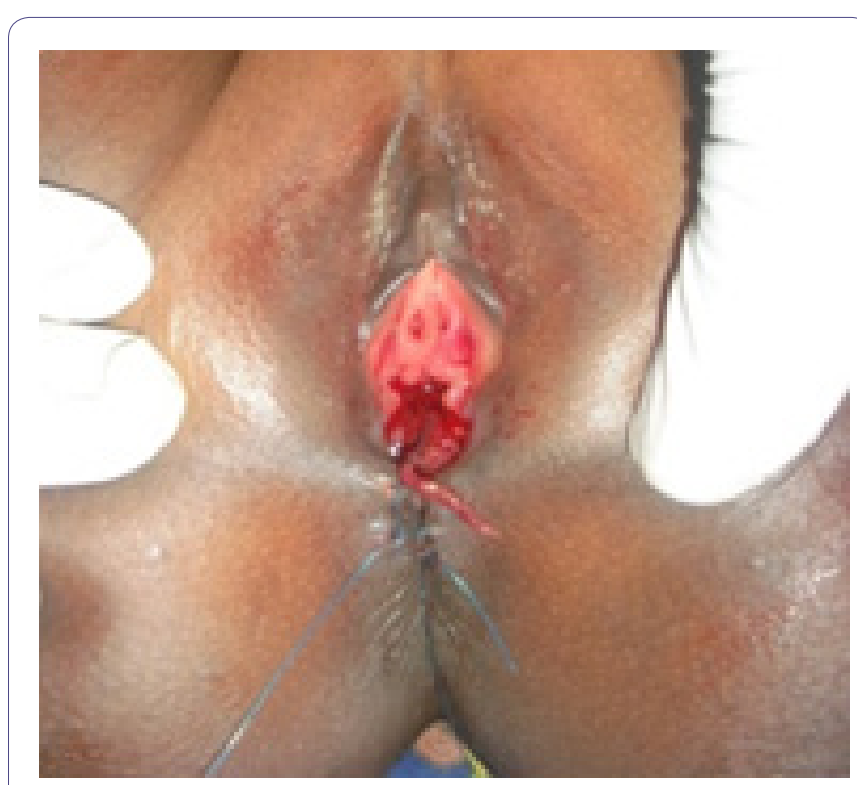

Figure 2: Stitches at the anal margin, done by a nurse just after trauma in the girl of 8 years old (Patient 3 ).

The patient 4 presented with anal yawning, superficial and radial wounds at 1, 5, 7, 10 and 11 oclock lithotomy (Figure 4). A radial wound at 6 oclock lithotomy continued on $3 \mathrm{~cm}$ on the anal mucous membrane, where it was deep, till the muscular layer (Figure 5). This injury was classified grade II.

The treatment needed left transverse colostomy in patients 1 and 2. The colostomy was closed 4 weeks later, in the same operative time of repair of the rectovaginal septum in patient 1 . She was kept on fasting during 7 days after the repair. The patient 2 had in emergency an abdominal exploration that showed sigmoid colon perforation (Figure 6) and transfixing wound of the ileum (Figure 7). Those bowel injuries associated to the ART permitted to classify the injury grade V. We performed suture of sigmoid perforation, and resection and an end to end anastomosis of ileum. The colostomy was closed 5 weeks later. 


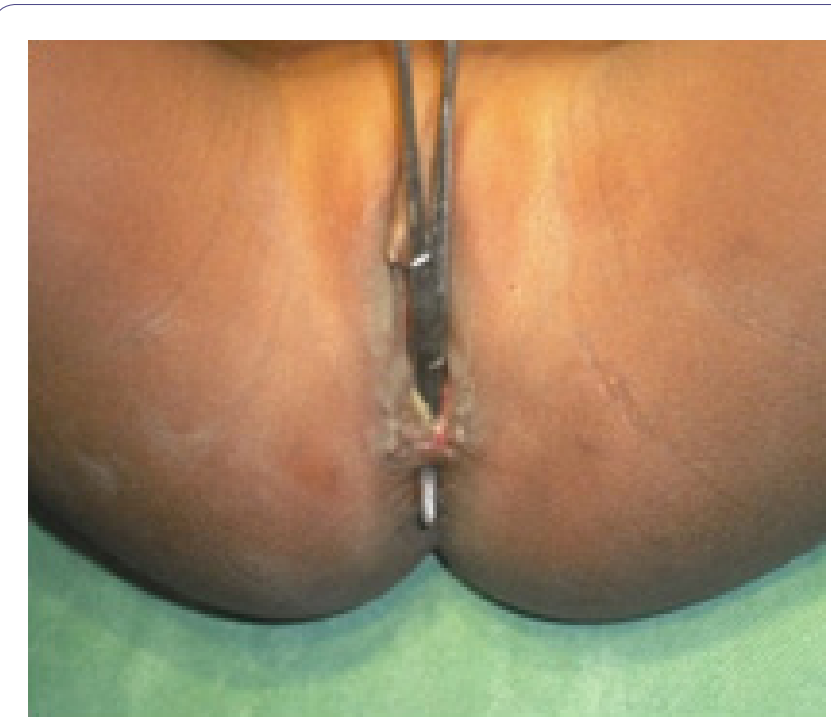

Figure 3: Rectovaginal fistula, showed by the clip after cutting of stitches (Patient 3).

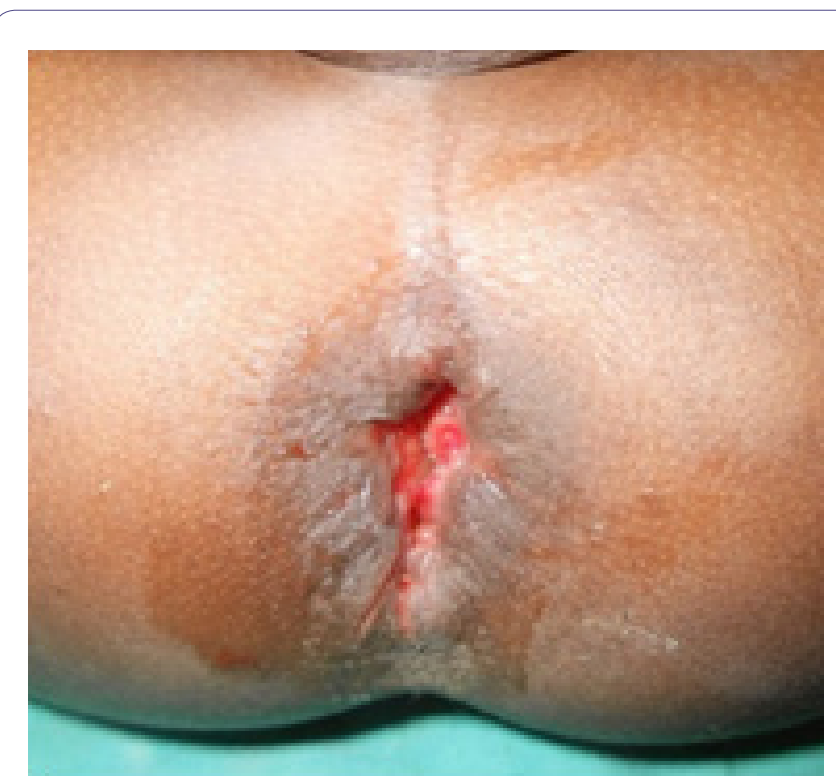

Figure 4: Anal yawning with radial wounds at the anal margin in the boy of 2.5 years old (Patient 4$)$.

For the patient 3 , after cutting stitches at the anal margin, we noticed that it was a rupture of the rectovaginal septum on $3 \mathrm{~cm}$; we therefore classify the injury grade II. The repair consisted of suture of each layer of the rectovaginal septum. She was kept on fasting during 5 days after the repair. The post operative periods of those 3 patients were uneventful. None of them presented trouble of defecation, and postoperative anuscopy was not done in any case. The patient 4 had not surgical repair; we did local application of antiseptics (twice daily sitz baths with Povidone iodine) and that led the wounds to heal by secondary intention. After healing, scars of radial wounds on anal margin disappeared in anal margin folds, and became non obvious.

All the patients had broad spectrum antibiotic treatment (ceftriaxone and Netilmicin), and tetanus prophylaxis.

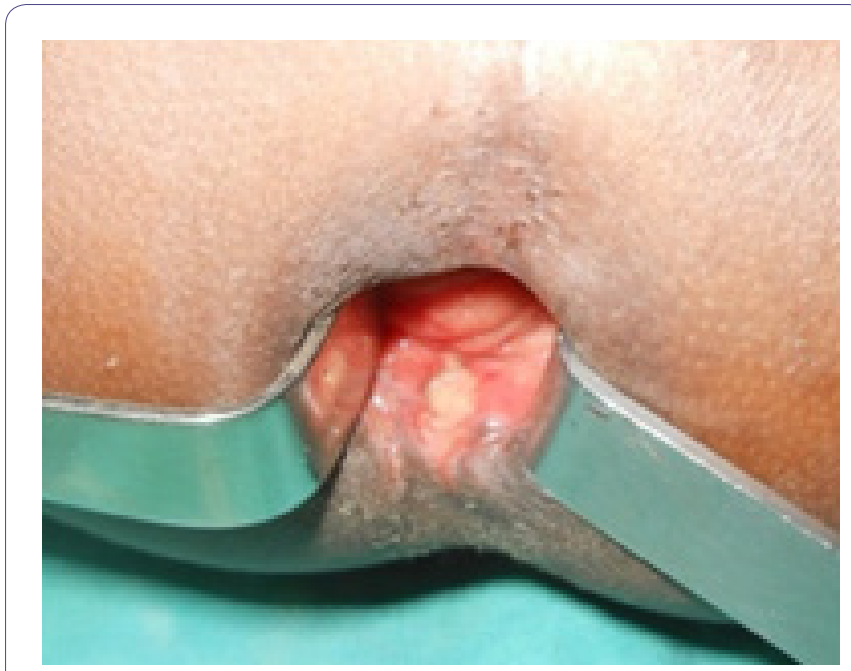

Figure 5: Deep wound at the posterior wall of anal canal in the boy of 2.5 years old (Patient 4).

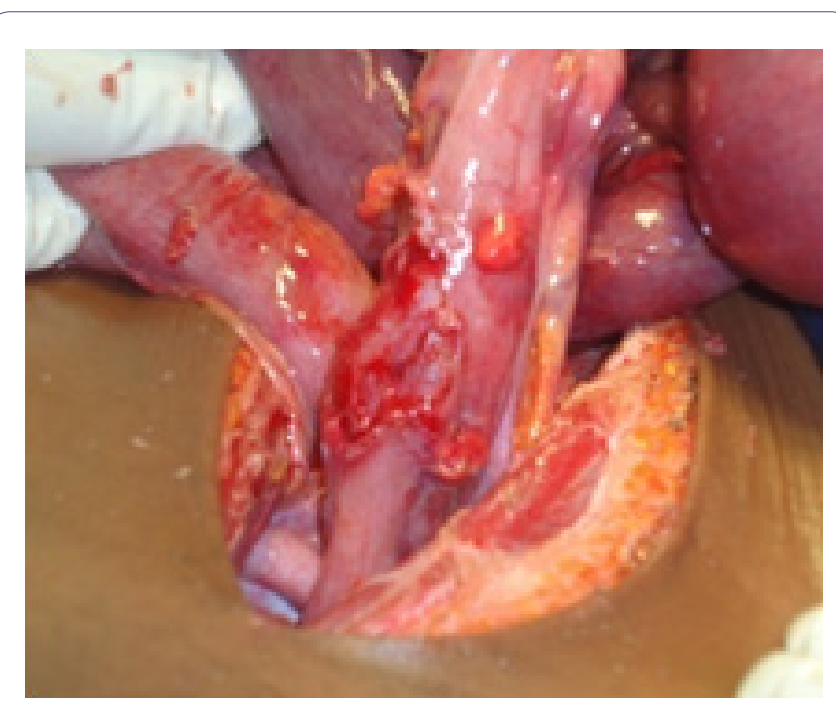

Figure 6: Sigmoid colon perforation by impalement in the boy of 13 years old (Patient 2).

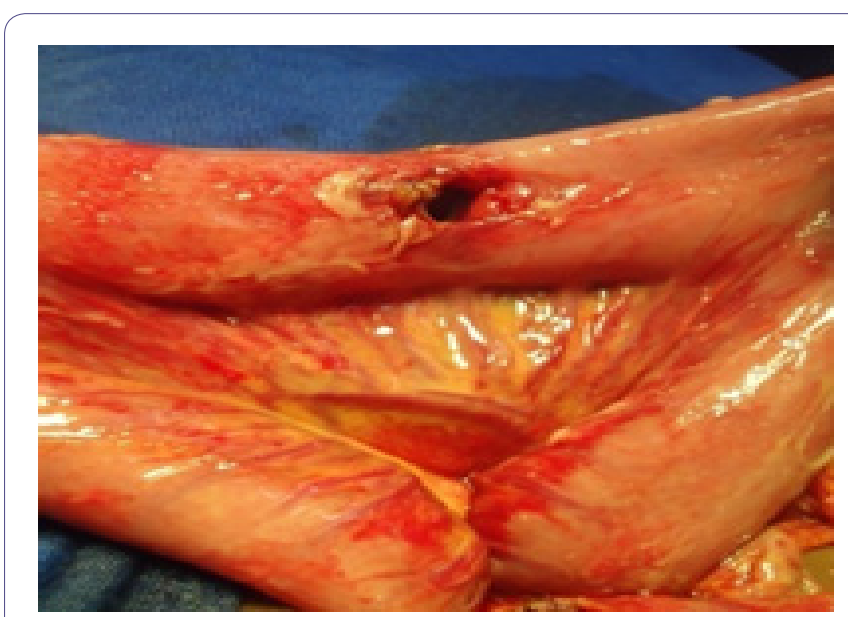

Figure 7: Transfixing wound of ileum by impalement in the boy of 13 years old (Patient 2). 
From the medico legal view point, the rapist of the patient 1 had never been found either by the family or the policemen; but the step-father of the patient 4 was immediately taken in for questioning and then jailed.

With respective follow-up of 42, 30, 26 and 11 months, the results were good with all; there were no complications, especially no case of anal sphincter insufficiency. According to Jorge and Wexner score, none of them had fecal incontinence; each patient had score 0 .

\section{Discussion}

The frequency of ART is variable. It is not a common trauma; few series of over 10 years collected more than 10 cases: 13 cases for Vincent MV et al., [3], 12 cases for Beiler et al., [6]. In West Africa, the most important published series is that of Ameh et al., [1]: 7 cases over 10 years. The distribution according to the sex changes from one series to another. Some series found male predominance [3,8], while others found female predominance $[1,6]$. Our series included 2 boys and 2 girls. Every age can be concerned by ART. The youngest patient in our series was aged 2.5 years. ART by sexual assault in an infant of 9 months has been reported [3]. Etiologies are multiple. Impalement or falling upon an offending objet is the most frequent mechanism $[3,6,10]$. The nature of the offending objet is variable; in the series of Vincent et al., [3], there were metal objects in 12 cases over 13, and those objects are part of malfunctioning bicycles. The offending objet can be sharp stumps or picket of wood as in 2 cases of our series, and in 2 cases of the series of Ameh E [1]. Other objects can cause impalement: fence [6], cow horn [1]. Road traffic accident was reported $[1,6]$. Sexual assaults are rare mechanism of ART in children [3]; but they were the main mechanism in the series of Black et al., [8]. They can concern either girls or boys. In our series, one girl and one boy had ART by sexual assault.

The diagnosis of ART ought to be done early after the trauma. In developed countries, patients are seen quickly in emergency after trauma. But in developing countries, poverty and low medical cover of population explain the delay to consultation. The delay can allow development of septic complications, and complicate the management. In the series of Ameh E [1], one patient was admitted after 24 hours, and 6 within 6 hours. As for our series, none was admitted within 6 hours after trauma; one was admitted after 3 days, and another after 6 days.

A methodic clinical exam permits to approach the diagnosis. At admission, hemodynamic parameters must be checked and resuscitation started if necessary. A clear description of the mechanism is important; it informs on the gravity of the trauma, and the organs that can be damaged. Rectal bleeding is the most frequent presentation $[1,3,5]$; it was seen in all our cases. Vaginal bleeding is associated in girls when the rectovaginal septum is hurt $[1,3]$. Urethral bleeding informs on bladder or urethral injury associated [1]. The perforation of the bladder can result in out-flow of urines throw the rectum after a suprapubic pressure during exam [7]. Rectoscopy and vaginoscopy (in girls) permit to precise the local extent of the injury. They can need general anesthesia to be well done, especially in infants and young children, as we did in our series. Abdominal exam must search for abdominal pain or tenderness. In our series, the boy of 13 years old was admitted 8 hours after the trauma with peritonitis signs. This is the proof of intraabdominal involvement, but also of the long delay to admission. Four patients with intraabdominal injuries in the series of Vincent et al., [3] didn't present peritonitis signs. In case of doubt on abdominal extent, an exploration by laparoscopy, instead of exploratory laparotomy is useful.
Clinical exam with rectoscopy / vaginoscopy and abdominal findings permit to classify the injury, and choose the adapted management. We used the classification of Black et al., [8], but we consider also the delay to admission. The classification of Jona JZ [11] includes all possibilities, especially for transanal injuries and seems to be more complete. The patient 2 of our series was classified grade $\mathrm{V}$ of Black et al., [8] because of intraperitoneal injuries associated; but he had not full thickness injury of canal anal or rectum. It was a transanal intraperitoneal injury. One can be surprised to have intraperitoneal injuries without anal margin lesions in transanal intraperitoneal injury. This possibility is an important point of the classification of Jona JZ [11]. In our case, (patient 2), we think that the underpants and the panties that the patient wore, covered the picket while it penetrated the anal canal. The picket would have passed through the clothes once in the anal canal, so the anal margin was protected.

For the treatment, the surgeon has to decide about colostomy and primary repair. Some protocols or algorithms for management were proposed [1-3]. Colostomy is indicated in cases with intraperitoneal involvement, anterior rectal wall injuries, bladder injuries, "complex" extraperitoneal rectal injuries and important perineal tissue destruction [3]. If the intraperitoneal involvement is doubtful, a laparoscopic exploration instead of exploratory laparotomy is indicated. According to the classification of Black et al., [8], it is indicated in grades III, IV and V $[1,8]$. In our conditions, colostomy is also indicated for injuries admitted with long delay. The patient 1 of our series, admitted 19 hours after the trauma could have benefited from primary repair without colostomy if she had been admitted earlier. The patient 3 of our series admitted 6 days after the trauma, had a "primary" repair without colostomy. In fact, her injury was not left without treatment; she had a "bad treatment" so we decided to do the repair without colostomy at her admission and the postoperative period was uneventful. Without colostomy in indicated situations, infection risk is very high $[1,3]$ and can threaten the life of the child [1]. With early admission, primary repair can be done in quite all cases, for accessible injuries. Non accessible injuries of rectum can heal with rectal drainage associated to colostomy [1]. With late admission, injuries that needed primary repair could heal in secondary intention [3] as in our Patient 4 , or with secondary repair after colostomy as in our Patient 1.

The outcome is always good. The anal continence is maintained, even in patients with external-sphincter injuries [1].

\section{Conclusion}

ART are rare injuries, but need an adapted management. Many protocols of management are proposed. In developing countries, the delay to admission imposes some particularities in the management. Those particularities are important, and permitted us to have good result in all our cases.

\section{References}

1. Ameh EA (2000) Anorectal injuries in children. Pediatr Surg Int 16: 388-391.

2. Grisoni ER, Hahn E, Marsh E, Volsko T, Dudgeon D (2000) Pediatric perineal impalement injuries. J Pediatr Surg 35: 702-704.

3. Vincent MV, Abel C, Duncan ND (2012) Penetrating anorectal injuries in Jamaican children. Pediatr Surg Int 28: 1101-1107.

4. Bronkhorst MW, Wilde JC, Hamming JF, Heij HA (2007) Anorectal impalement in a pediatric patient with transanal evisceration of small bowel. J Pediatr Surg 42: 23-25. 
5. Akakpo-Numado GK, Boume MA, Mihluedo-Agbolan KA, Simlawo K, Adabra $\mathrm{K}$ (2014) Perforation of large and small intestines by impalement in a 13-yearold boy. J Ped Surg Case Reports 2: 206-208.

6. Beiler HA, Zachariou Z, Daum R (1998) Impalement and anorectal injuries in childhood: a retrospective study of 12 cases. J Pediatr Surg 33: 1287-1291.

7. Johnson PA (1971) Rectal impalement with perforation of the bladder. $\mathrm{Br}$ Med J 2: 748-749.

8. Black CT, Pokorny WJ, McGill CW, Harberg FJ (1982) Ano-rectal trauma in children. J Pediatr Surg 17: 501-504.
9. Jorge JM, Wexner SD (1993) Etiology and management of fecal incontinence. Dis Colon Rectum 36: 77-97.

10. Yao JG, Masso-Misse $P$, Malonga $E$ (1994) Ano-rectal injuries in civilian practice in Cameroon. 10 case reports. Med Trop (Mars) 54: 157-160.

11. Jona JZ (1997) Accidental anorectal impalement in children. Pediatr Emerg Care 13: 40-43. 